\title{
A FAMÍlIA COMO ORDEM SIMBÓLICA
}

\author{
Cynthia Andersen Sarti ${ }^{1}$ \\ Escola Paulista de Medicina - UNIFESP
}

\begin{abstract}
Este texto trata de questões relativas ao trabalho com famílias, em particular, com o jovem na família. Baseia-se em uma concepção de família como uma realidade de ordem simbólica, que se delimita por uma história contada aos indivíduos e por eles reafirmada e ressignificada, nos distintos momentos e lugares da vida familiar, considerando a relação da família com o mundo externo. Diante de referências culturais e sociais diversas, a análise da família exige um esforço de estranhamento, nem sempre fácil, sobretudo, porque tendemos a confundir família com a "nossa" família. Enfatiza-se, assim, a importância de se escutar a história das famílias como um outro ponto de vista, distinto daquele do profissional ou pesquisador, mas fundamental e igualmente legítimo na elaboração das experiências vividas por famílias em alguma situação de vulnerabilidade.
\end{abstract}

Descritores: Família. Cultura. Etnocentrismo. Jovens. Alteridade.

$\mathrm{E}$ ste texto pretende discutir questões relativas ao trabalho com famílias e, em particular, com o jovem na família -, que aparecem freqüentemente no atendimento à saúde, tanto no que se refere ao cuidado quanto ao processo de adoecer, no qual a família está também implicada. Sua preocupação central é a dificuldade que o tema apresenta, por se referir a uma realidade que nos é muito próxima e com a qual tendemos a nos confundir. Exige um esforço de estranhamento, nem sempre fácil, quando estão em jogo outros pontos de vista, diferentes de nossas próprias referências cultu-

1 Endereço institucional: Universidade Federal de São Paulo, Departamento de Medicina Preventiva, Rua Borges Lagoa, 1341, $1^{\circ}$ andar, CEP 04038-034, São Paulo-SP. Fone/Fax: (11) 5572-0609. Endereço eletrônico: csarti@ uol.com.br 
rais e sociais. Essa dificuldade emerge mais claramente no atendimento às famílias pobres.

A discussão busca responder, ainda, à tendência atual das políticas sociais, em geral, e das políticas de saúde, em particular, de tomar a família - e não o indivíduo isoladamente - como unidade de atendimento. ${ }^{3}$ Como sintetizou Marsiglia (2003), essa tendência pode ser observada em várias orientações: desinternação ou desospitalização, de doentes crônicos físicos ou mentais; redução do tempo de internação, nas doenças graves; e ênfase no atendimento domiciliar, tanto no caso de doentes graves e crônicos, como no da assistência aos idosos. O problema reside em que não necessariamente se levam em conta as implicações dessa estratégia.

Sendo a família um mundo de relações (Sarti, 2003a, 2003b), o atendimento que focaliza a família lida forçosamente com esse mundo de relações, em todo seu emaranhado de situações e pontos de vista. Quando se enfoca a família, então, a primeira coisa a se ter em conta é que se está tratando de relações e não de indivíduos, o que contraria a formação dos profissionais de saúde, em geral, que tendem a operar a partir de uma noção individualizada e objetivada do corpo e da doença, com base no modelo biomédico, distante desse universo não palpável, mas sempre atuante, das relações intersubjetivas que ocorrem no âmbito familiar.

As reflexões aqui sugeridas baseiam-se, sobretudo, em experiências de pesquisa etnográfica com famílias nos bairros da periferia da cidade de São Paulo, nas quais focalizei a construção da noção de família pelos moradores desses locais da cidade, onde vive a população pobre, desfavorecida

2 Estas reflexões foram originalmente apresentadas no Seminário Internacional sobre a Criança e o Jovem na América Latina, organizado pela Faculdade de Filosofia e Ciências da Universidade Estadual Paulista (UNESP), Campus de Marília, novembro de 2001. Em torno de outros eixos de preocupação, os principais argumentos aqui desenvolvidos estão também presentes em artigos anteriores sobre jovens e família (Sarti, 1999), um deles recentemente publicado em coletânea (Sarti, 2004).

3 Como é o caso do Programa de Saúde da Família (PSF), implantado pelo Ministério da Saúde, em parceria com os municípios, como parte da política de descentralização da atenção em saúde. 
em relação aos valores sociais da riqueza, do prestígio e do poder e para quem, em contrapartida, a família configura precisamente um valor. Este trabalho de pesquisa revelou a família como uma referência simbólica fundamental para a população pobre, que ordena o lugar dos indivíduos no mundo social como um todo, dentro e fora da família (Sarti, 1995, 2003a).

A partir dessas experiências, em lugar de definir a família por meio de uma conceituação a priori, que supostamente serviria de ferramenta para o trabalho, este texto propõe pensar a noção de família como uma "categoria nativa", ou seja, a partir do sentido a ela atribuído por quem a vive, considerando-o como um ponto de vista. Embora nunca estejamos inteiramente seguros de que o que atribuímos ao outro corresponde ao que ele atribui a si mesmo, dificuldade inerente às relações intersubjetivas, pode-se, pelo menos, buscar uma abertura no sentido dessa aproximação ao outro, que caracteriza a prática etnográfica.

Pretende-se sugerir, assim, uma abordagem de família como algo que se define por uma história que se conta aos indivíduos desde que nascem, ao longo do tempo, por palavras, gestos, atitudes ou silêncios e que será, por eles, reproduzida e re-significada, à sua maneira, dados os distintos lugares e momentos dos indivíduos na família. Vista como uma realidade que se constitui pela linguagem, socialmente elaborada e internalizada pelos indivíduos, a família torna-se um campo privilegiado para se pensar a relação entre o individual e o coletivo, portanto, entre mim e o outro.

\section{Família e cultura}

Partimos, então, da idéia de que a família se delimita, simbolicamente, a partir de um discurso sobre si própria, que opera como um discurso oficial. Embora culturalmente instituído, ele comporta uma singularidade. Cada família constrói sua própria história, ou seu próprio mito, entendido como uma formulação discursiva em que se expressam o significado e a explicação da realidade vivida, com base nos elementos objetiva e subjetivamente acessíveis aos indivíduos na cultura em que vivem. Os mitos familiares, 
expressos nas histórias contadas, cumprem a função de imprimir a marca da família, herança a ser perpetuada.

Pensar a família como uma realidade que se constitui pelo discurso sobre si própria, internalizado pelos sujeitos, é uma forma de buscar uma definição que não se antecipe à realidade da família, mas que nos permita pensar como a família constrói, ela mesma, sua noção de si, supondo evidentemente que isso se faz em cultura, dentro, portanto, dos parâmetros coletivos do tempo e do espaço em que vivemos, que ordenam as relações de parentesco (entre irmãos, entre pais e filhos e entre marido e mulher). Sabemos que não há realidade humana exterior à cultura, uma vez que os seres humanos se constituem em cultura, portanto, simbolicamente.

Quando ouvimos as primeiras falas, não aprendemos apenas a nos comunicar, mas, acima de tudo, captamos uma ordem simbólica, ou seja, uma ordenação do mundo pelo significado que lhe é atribuído, segundo as regras da sociedade em que se vive. O componente simbólico, apreendido na linguagem, não é apenas parte integrante da vida humana, mas é seu elemento constitutivo, ponto de partida da Antropologia Social, tanto em sua vertente norte-americana (Geertz, 1978, 1980) quanto francesa. Nessa última, Mauss (1974 [1923-1924]), ao conceber a realidade social como um universo simbólico, ressaltou o caráter inconsciente dos costumes internalizados sem que os indivíduos percebam. Uma abordagem que permanece fecunda para a apreensão do mundo social, por articular dialeticamente as dimensões objetiva e subjetiva. Como mostrou Lévi-Strauss (1974), em sua análise da obra de Mauss, o costume passa a ser visto como da ordem da linguagem, pois os agentes não têm consciência de suas regras. Assim como a gramática da língua não é percebida pelos falantes, tampouco a gramática da vida social, pelos seus agentes.

Nesse jogo entre o mundo exterior e o mundo subjetivo, as construções simbólicas operam numa relação especular. Assim acontece na família. O discurso social sobre a família se reflete nas diferentes famílias, como um espelho. Em cada caso, entretanto, há uma tradução desse discurso, que, por sua vez, devolverá ao mundo social sua imagem, filtrada pela singularidade 
das experiências vividas. Assim, cada família constrói seus mitos a partir do que ouve sobre si, do discurso externo internalizado, mas devolve um discurso sobre si que contém também sua própria elaboração, objetivando sua experiência subjetiva.

Essa formulação é, evidentemente, contrária à identificação da noção de família com a unidade de reprodução biológica (pai, mãe e filhos) e se contrapõe, ainda, à suposição da biologia humana como parte da ordem da natureza. Essa naturalização das relações sociais acontece de forma mais clara em relação à família do que a outras instituições sociais, porque a família é o espaço social onde se realizam os fatos da vida vinculados ao corpo biológico, como o nascimento, a amamentação, o crescimento, o acasalamento, o envelhecimento e a morte. $\mathrm{O}$ apelo à ordem da natureza para explicar fatos humanos remete à dissociação entre biologia e cultura, com base na qual se assume que o corpo biológico existe independentemente da cultura, ao invés de pensá-lo como inscrito na e pela cultura. Em artigo anterior (Sarti, 2001), tratei mais detalhadamente da relação entre corpo biológico e cultura, tema significativo na antropologia brasileira (Castro, 1987; Clastres, 1990; Leal, 1995; Rodrigues, 1979, entre outros).

Nesse sentido, é interessante ressaltar a reordenação simbólica provocada pelas novas tecnologias reprodutivas, que, ao desvincularem a reprodução biológica das relações sexuais e atribuírem um caráter artificial à procriação, um dos mais naturalizados entre os fatos humanos, quebram a identificação do corpo biológico com a ordem natural tão difundida em nossa cultura. Esses avanços tecnológicos, tais como a pílula anticoncepcional, que desvinculou sexualidade e reprodução, ao lado da descoberta do teste de DNA, que permite a comprovação da paternidade biológica, provocam mudanças nas práticas e nos valores familiares, mas também mostram onde se localizam as resistências (Fonseca, 2001; Scavone, 1998, 1999). A importância de acolher e não condenar as famílias constituídas a partir das possibilidades das novas técnicas de reprodução, incluindo os filhos de casais hmossexuais, foi discutida no diálogo de Roudinesco e Derrida (2001) e retomada em Roudinesco (2003). 
As mudanças são particularmente difíceis, uma vez que as experiências vividas e simbolizadas na família têm como referência definições cristalizadas de família socialmente instituídas pelos dispositivos jurídicos, médicos, psicológicos, religiosos e pedagógicos, enfim, os dispositivos disciplinares existentes em nossa sociedade, que têm nos meios de comunicação um veículo fundamental, além de suas instituições específicas. Essas referências constituem os "modelos" do que é e deve ser a família, fortemente ancorados numa visão de família como uma unidade biológica constituída segundo as leis da "natureza". A pergunta a ser formulada, então, é: no atendimento a famílias, como romper esses modelos sociais internalizados e como escutar os discursos das próprias famílias sobre si, nessa permanente tensão entre a singularidade de cada uma e as referências sociais das quais não podemos escapar?

\section{$O$ atendimento a famílias}

Quando se trabalha com famílias, tanto cientistas sociais, quanto psicólogos, médicos, educadores e outros profissionais enfrentam um primeiro problema: o de identificar a noção de família com suas referências pessoais. A família tende a ser identificada com a "nossa" família, tão forte é a identificação da idéia de família com o que nós somos. Por isso, quando se lida com questões de família, é difícil estranhar-se em relação a si mesmo. Há uma tendência a projetar a família com a qual nos identificamos - como idealização ou como realidade vivida - no que é ou deve ser a família, o que impede de olhar e ver o que se passa a partir de outros pontos de vista.

Nos temas referentes à família, há uma tendência ao etnocentrismo, maior ainda da que habitualmente existe em outros assuntos: olha-se para o outro a partir das próprias referências, espelhando a realidade exterior naquilo que é "familiar", sem enxergá-la em sua maneira de se explicar a si mesma. Traduz-se o estranho em termos "familiares", o que impede o movime nto de estranhamento necessário para relativizar nosso próprio olhar. Da Matta (1978) fala nos dois movimentos que considera fundamentais na pes- 
quisa etnográfica: o de "transformar o exótico em famíliar" e o de "transformar o familiar em exótico". Ele argumenta que o primeiro movimento pressupõe o segundo, ou seja, não somos capazes de enxergar o outro e aceitá-lo, se não conseguirmos nos estranhar em relação ao que somos. A dificuldade está em que esse movimento implica uma operação que não é apenas de ordem intelectual, mas sim, emocional.

Além disso, a já comentada naturalização das relações familiares, junto à sua transformação num modelo a ser seguido, faz da família um terreno fértil para um discurso normativo, o que cria outro problema no trabalho com famílias. Há, freqüentemente, um "dever ser" no horizonte, referência positiva a partir da qual todo o resto torna-se "desvio" ou "anormalidade", quando não, "patologia".

A família é o lugar onde se ouvem as primeiras falas, com as quais se constrói a auto-imagem e a imagem do mundo exterior. Assim, é fundamentalmente como lugar de aquisição de linguagem que a família define seu caráter social. Nela, aprende-se a falar e, por meio da linguagem, a ordenar e dar sentido às experiências vividas. A família, seja como for composta, vivida e organizada, é o filtro através do qual se começa a ver e a significar o mundo. Esse processo que se inicia ao nascer estende-se ao longo de toda a vida, a partir dos diferentes lugares que se ocupa na família.

A família, inclusive para os adultos, continua tendo essa função de dar sentido às relações entre os indivíduos e servir de espaço de elaboração das experiências vividas. Essa concepção permite pensar o processo de "crescimento" na família como uma questão que diz respeito não apenas às crianças, mas a todos os seus membros, ao longo de suas vidas, na medida em que as experiências podem ser permanentemente re-elaboradas. "Crescer", assim, desvincula-se do mero processo biológico e constitui-se, também, em um processo simbólico. As condições favoráveis para que uma criança "cresça" ou um jovem se desenvolva na família se ampliam quando seu pai, sua mãe ou quem deles cuide possam se pensar, eles mesmos, como alguém em permanente crescimento, em cada novo lugar que ocupe na família. 
A própria noção de crescimento é posta em questão, pelos pressupostos evolucionistas nela contidos, ao supor "etapas" a serem superadas dentro de um caminho pré-determinado, independente das particularidades cult urais e do contexto social. Nesse sentido, cabe remeter a crítica de James, Jenks e Prout (1998) ao caráter evolucionista das teorias sobre o desenvolvimento infantil, dada a linearidade e a idéia de progresso implícitas em suas concepções. Nesse mesmo sentido, Rabinovich (1995) questiona a validade de se definir um padrão de desenvolvimento infantil, a partir de estudos descontextualizados.

A família não se define, portanto, pelos indivíduos unidos por laços biológicos, mas pelos significantes que criam os elos de sentido nas relações, sem os quais essas relações se esfacelam, precisamente pela perda, ou inexistência, de sentido. Se os laços biológicos unem as famílias é porque são, em si, significantes. Ninguém se atreveria a contestar a força simbólica dos "laços de sangue" em nossa cultura ibérico-ocidental, com os "nomes de família", as semelhanças físicas, os traços de personalidade (ou de caráter) "que se puxa" de algum parente próximo ou distante... (Sarti, 1999).

As fronteiras da família, delimitadas pela história que vai sendo contada aos indivíduos ao longo de suas vidas, são, entretanto, constantemente redefinidas pelas várias mensagens que lhes chegam, vindas do mundo ao seu redor. Além disso, cada um conta essa história do seu jeito. Ela é recontada de maneiras diferentes por e para cada um dos membros que compõem a família, dependendo do lugar a partir do qual ouvem e falam, construindo várias (e variadas) histórias.

Os discursos são distintos porque os lugares são diferenciados. O discurso muda não apenas de acordo com quem fala, mas também em relação a quem se fala. A família, como o mundo social, não é uma soma de indivíduos, mas sim um universo de relações. Embora comporte relações potencialmente eqüitativas, como aquela entre o homem e a mulher, a família implica autoridade, pela sua função de socialização dos menores, definindo-se, assim, como um mundo de relações recíprocas, complementares e assimétricas. 
Crescer significa, precisamente, poder relativizar as referências familiares, desnaturalizando-as, o que permite o processo de singularização, tanto das famílias frente aos modelos, quanto do sujeito diante das imposições familiares. Esse processo atualiza-se permanentemente ao longo da vida, o que implica que, tratando-se de relações familiares, haja sempre o que fazer... Um mau começo dificulta a vida adulta, mas não impede o "crescimento" - entendido não verticalmente, mas horizontalmente, como mudanças de lugares -, se novas possibilidades se abrirem no caminho. No mundo atual, essa abertura pode se dar, cada vez mais cedo, desde os berçários e creches, uma vez que a educação das crianças é considerada também uma responsabilidade social, de instituições públicas, fora do âmbito fa miliar.

Os limites do mundo familiar, demarcados pela história que a família conta sobre si, criando sua identidade, são abalados pela ação individualizada de cada um de seus membros, que reagem singularmente às relações internas e que trazem à convivência cotidiana a experiência também singular com o mundo exterior.

A tensão entre os distintos discursos familiares denota a singularidade da família no mundo contemporâneo: ela é, ao mesmo tempo, auto-referida na sua construção do "nós" - nisto que constit ui o mundo privado - e permanentemente influenciada pelo mundo exterior - público -, que lhe traz a inevitável dimensão do "outro", com a qual tem que lidar. Assim, a família constitui-se pela construção de identidades que a demarcam, em constante confronto com a alteridade, cuja presença se fará sentir insistentemente, forçando a abertura, mesmo quando persistirem as resistências. A família, então, constitui-se dialeticamente. Ela não é apenas o "nós" que a afirma como família, mas é também o "outro", condição da existência do "nós". Sem deixar entrar o mundo externo, sem espaço para a alteridade, a família confina-se em si mesma e se condena à negação do que a constitui, a troca entre diferentes.

Essa marca da família, a troca, remete à reviravolta eita por LéviStrauss na sua formulação sobre o tema, conhecida como teoria da aliança. Ao argumentar em favor do fundamento social (e não natural) da família, 
afirma que a família se constitui pela aliança (entre famílias previamente existentes) e não pela consangüinidade, que se torna uma consequiência da aliança (o casamento). Se a família - instituição humana, portanto cultural não incorpora o outro em suas relações, fechando-se em si mesma, nega o que constitui seu próprio fundamento: o rompimento do isolamento das relações naturais de consangüinidade para a expansão por meio dos laços sociais de aliança com o diferente, através do casamento. Assim, para LéviStrauss (1981[1947]), o tabu do incesto, "a" intervenção social, não é apenas uma regra negativa, uma proibição simplesmente, mas uma regra positiva, a da reciprocidade, que é abertura ao outro, condição de possibilidade de a humanidade desenvolver-se culturalmente.

\section{Família e jovens}

Nessa linha de argumentação, pretende-se sugerir o lugar do jovem na família como aquele de quem introduz uma alteridade na família, por meio de novos discursos que abalam seu discurso oficial - seja pela ruptura ou pela inversão ou, mesmo, pela reafirmação deste discurso. Reações diversas - de fechamento ou de abertura frente a esses "estranhos" - serão decisivas para as relações familiares e, particularmente, para o lugar do jovem, em busca de uma identidade própria que se constrói pelas várias alteridades com as quais se enfrenta.

Os jovens caracterizam-se precisamente pela busca de outros referenciais para a construção de sua identidade fora da família, como parte de seu processo de afirmação individual e social. Necessitam falar de si no plural, recriando "famílias" (como construção de "nós"), fora de seu âmbito familiar de origem, através dos vários grupos de pares (peer groups), seja em torno de música (rock, rap), outras atividades culturais, esportivas ou outras formas de expressão dos jovens no espaço público. Heller (1996) comenta que a sensação de "estar em casa", no mundo moderno, prescinde da experiência espacial da casa, o que permite aos filhos em conflito com os pais que se sintam mais "em casa" com seu grupo de pares do que com sua família, 
vista como "estranha". Essa experiência será evidentemente social e culturalmente diferenciada, de acordo com os recursos disponíveis para cada família.

$\mathrm{Na}$ relação dos jovens com a família joga um papel fundamental a forma como esta incorpora esses "outros" estranhos ao meio fa miliar que o jovem traz para casa, porque ele neles se reconhece, sendo parte essencial da sua busca de sentido para a sua existência pessoal. A disponibilidade e a definição dos limites da família para deixar entrar, aceitar e lidar com esses outros do mundo jovem serão determinantes das relações na família nesse momento de sua vida.

Nesse ponto, é fundamental mencionar também o papel dos meios de comunicação, sobretudo, o da televisão e o da publicidade, no sentido de criar referências de identidade para os jovens, que a família não possa ignorar, dada a exposição de todos os segmentos sociais a suas mensagens. Isso é particularmente importante diante do risco, mencionado por Giberti (1996), do que chama de "uma forma de autismo", produzido pelos meios de comunicação nos indivíduos em família, que passam a não se relacionar entre si, estando presentes, mas conectados aos meios e não uns aos outros, sobretudo nas famílias de camadas médias e altas que, agora, dispõem também de computadores e acesso à internet .

A importância fundamental da família para o jovem está precisamente nessa possibilidade de manter o eixo de referências simbólicas que a família representa, como lugar de apego, de segurança, como rede de proteção, mas que nesse momento - mais radicalmente, ainda, do que em outros do ciclo de vida familiar - precisa abrir espaço para o outro, justamente para continuar a ser ponto de referência.

O período da adolescência significa uma mudança no estatuto social do sujeito. Neste sentido, cabe observar a ausência, em nossa sociedade, de rituais socialmente compartilhados, que permitam simbolizar essa nova posição social. Nas sociedades tribais e tradicionais, por exemplo, há os ritos de passagem, como aqueles das sociedades sem escrita, que, segundo a análise de Clastres (1990), inscrevem suas marcas nos corpos, fazendo desses rituais 
verdadeiras provas de coragem e força que habilitam o proponente a ingressar legitimamente no mundo considerado adulto, conforme suas regras.

Em nossa sociedade, pode-se dizer que tanto a adolescência, como a juventude, deixaram de configurar um momento de passagem, mas tampouco têm lugar definido. Na ausência de rituais que instituam esse momento como uma nova posição social, cuja marca não seja o estado de liminaridade e de transição, o jovem vive seu lugar como o da contestação, como um "outro" lado, em contraposição ao mundo adulto. Ele é um não-adulto e, freqüentemente, um problema para o mundo adulto, o "aborrecente". Em contraposição a essa idéia, a proposta de desenvolver o "protagonismo juvenil" nos programas para jovens aponta para a importância de pensá-los como agentes de soluções para seus próprios problemas.

Pode-se supor, então, que no lugar socialmente designado para o jovem/adolescente há uma projeção do mundo adulto em sentidos distintos. Em primeiro lugar, como objeto das expectativas familiares, os jovens têm os rumos de suas vidas traçados por seus pais de forma a cumprir o que a família espera para si. São conhecidos os conflitos deflagrados pela resistência dos jovens a concretizar essa forma de herança e de perpetuação de sua "família". Gostaria, entretanto, de atentar para outra forma de projeção que se refere à tendência a localizar no jovem as situações que configuram problema para a família, eximindo o mundo adulto de nelas se incluir. Grande parte da dificuldade de lidar com as questões juvenis, sobretudo aquelas ligadas à sexualidade, a escolhas ou indagações existenciais, tem a ver com o fato de que tocam em pontos difíceis para os pais, em suas próprias vidas. Transferem-se para o jovem essas questões que se transformam em "problema do jovem", próprio de uma suposta etapa da vida, tratado isoladamente, na busca vã de que se restabeleça alguma calma, que corre o risco de instituir uma "violência da calmaria" que, como mostra Roudinesco (2000), "pode ser mais terrível do que a travessia das tempestades" (p. 17), pelo que implica de negação.

A negação do diferente, a base etnocêntrica de todo o preconceito, funda-se precisamente na dificuldade de aceitar que o suposto diferente se 
parece muito conosco e pode nomear o que para nós é inominável. Na verdade, ele revela muito de nós mesmos e põe em questão o caráter absoluto de nossas próprias referências culturais. Se o outro pode estar certo, então, isso significa que nós podemos estar errados? Essa é a ameaça implícita, difícil de enfrentar, como mostrou Rocha (1994), e que os jovens freqüentemente representam para a família.

A questão das "drogas", considerada um problema que acomete sobretudo jovens/adolescentes, ilustra essa transferência antes referida. Um dos mais sérios temores de pais de adolescentes, transformado num fantasma familiar, esse problema social é "satanizado", pela mesma lógica com que se "sacralizam" os valores familiares e impede que estes sejam discutidos e revistos nas diferentes circunstâncias. Na tentativa de lidar com o problema da "drogadição" e com os danos e consequiências devastadoras que pode acarretar, muita energia é mobilizada para livrar-se da "droga" em si, desconsiderando os mecanismos, não apenas psíquicos, mas também sociais e culturais, que levam o jovem a se relacionar com o mundo à sua volta de uma forma que fere sua autonomia e sua possibilidade de escolher. Nesse deslocamento, tampouco se levam em conta outros hábitos, porque socialmente aceitos, e que podem refletir o mesmo problema, como a relação compulsiva com o trabalho (os workoholics), os remédios sem os quais não se consegue dormir, entre outros. Localiza-se o mal no que se considera "droga", atribuindo-lhe caráter ontológico. Tratado como se fosse uma monstruosidade, esse "ser" deve, então, ser extirpado para que outra vez se restabeleça a ilusão da calma, mas os mecanismos permanecem, voltando, muito provavelmente, a se reproduzir sob outras formas.

Essa projeção dos problemas familiares sobre os jovens da família nos fala da dificuldade de lidar com conflitos no interior das famílias. A negação ou a dificuldade de se incorporar e dar algum espaço para o conflito na família, com os elementos simultaneamente disruptivos e potencializadores nele contidos, podem favorecer, inclusive, a eclosão da violência, sob distintas formas, que viria justamente da falta de canais de expressão para os conflitos próprios das relações familiares. 
Pelo lugar que ocupa socialmente, o jovem se afirma opondo-se, fazendo do conflito um instrumento tão necessário quanto imprescindível em seu processo de tornar-se sujeito, na família e no mundo social. Dessa maneira, a família configura um cenário onde o conflito é intrínseco e, sendo assim, o trabalho com famílias pode se dar no sentido de pensar os limites do que é ou não negociável nas relações familiares, a partir da indagação sobre o que constitui conflito para a própria família e não como uma definição externa.

\section{Considerações finais}

Soa óbvio mencionar a importância de se perguntar como a própria família define seus problemas, suas necessidades, seus anseios e quais são os recursos de que ela mesma dispõe. Menos óbvio é pensar como ouvimos as respostas e o estatuto que atribuímos ao que se diz. Voltamos à questão inicial da relação entre mim e o outro.

O problema reside não tanto na dificuldade de reconhecimento e aceitação do conflito por parte dos membros das famílias que os vivenciam, mas principalmente na concepção de família que subjaz à grande parte das "intervenções" em famílias, o que inibe a possibilidade de elaboração dos problemas individuais e coletivos a partir de recursos que podem estar no próprio âmbito familiar.

Duas questões estão em jogo: de um lado, a idealização da família, projetada num dever ser, e da própria afetividade como um mundo que exclui o conflito; mas, de outro lado, está a idealização de si, por parte dos profissionais, expressa na tendência a atribuir exclusivamente a si um saber, com base em sua formação técnica, e negar que a família assistida tenha um saber sobre si própria. Ouve-se o discurso das famílias como um não-saber, uma "ignorância", negando que esse discurso possa ser levado em conta como um diálogo entre pontos de vista. Essa tendência à desqualificação do outro será tanto mais forte quanto mais a família assistida pertencer aos es- 
tratos mais baixos da hierarquia social, reproduzindo os mecanismos que instituem a desigualdade social.

À dificuldade que o tema da família apresenta, por sua forte identificação com nossas próprias referências e pelo esforço de estranhamento que a aproximação ao outro exige, soma-se o problema do estatuto que atribuímos a nosso próprio discurso e, conseqüentemente, ao discurso do outro. Considerar o ponto de vista alheio envolve o confronto com nosso próprio ponto de vista, o que significa romper com o estatuto de verdade que os profissionais e pesquisadores tendem a atribuir a seu saber, relativizando seu lugar ao pensá-lo como um entre outros discursos legítimos, ainda que enunciados de lugares socialmente diferenciados. São conhecidos os obstáculos - de ordem narcísica - a essa démarche.

Sarti, C. A. (2004). The family as symbolic order. Psicologia USP, 15(3), 11-28.

\begin{abstract}
This text is concerned with questions about working with families, and with young people in the family in particular. It is based on a conception of family as a symbolic reality, which is framed by a story told to the individuals along their lifetime. This story is reaffirmed and resignified in different moments and places of family life, considering its relation to the external world. In face of diverse social and cultural references, family analysis demands a not always easy act of distancing oneself of one's own references, especially because we tend to confuse family with "our" family. The text, then, emphasizes the importance of listening to the family narratives from another point of view, different from the professional's or the researcher's, but fundamental and equally legitimate in the elaboration of the experiences lived by families in some kind of situation of vulnerability.
\end{abstract}

Index terms: Family. Culture. Ethnocentrism. Young adults. Alterity. 


\section{Cynthia Andersen Sarti}

Sarti, C. A. (2004). La famille en tant qu'ordre symbolique. Psicologia USP, 15 (3), 11-28.

Résumé: Ce texte développe des questions concernant le travail sur des familles, en particulier avec le jeune dans la famille. Il se fonde sur une conception de famille comme une réalité symbolique, qui se délimite par une histoire racontée aux personnes et par elles réaffirmée et re-signifiée, à des moments et lieux de la vie familiale distincts, en considérant toujours la relation de la famille avec le monde externe. En face d'autres références culturelles et sociales, l'analyse de la famille exige un effort d'éloignement pas toujours facile, surtout parce que nous avons la tendance à confondre famille avec "notre" famille. L'article souligne, ainsi, l'importance d'écouter l'histoire des familles avec un autre point de vue, différent de celui du professionnel ou chercheur, mais fondamental et également légitime dans l'élaboration des expériences vécues par les familles dans des situations de vulnérabilité.

Mots clés: Famille. Culture. Ethnocentrisme. Jeunes. Altérité.

\section{Referências}

Castro, E. V. de. (1987). A fabricação do corpo na sociedade xinguana. In J. P. de Oliveira Filho (Org.), Sociedades indígenas e indigenismo no Brasil (pp. 31-41). Rio de Janeiro: Marco Zero/UFRJ.

Clastres, P. (1990). Da tortura nas sociedades primitivas. In A sociedade contra o Estado (5a ed., pp. 123-131). Rio de Janeiro: Francisco Alves.

Da Matta, R. (1978). O ofício de etnólogo, ou como ter "anthropological blues". In E. O. Nunes (Org.), A aventura sociológica: objetividade, paixão, improviso e método na pesquisa social (pp. 23-35). Rio de Janeiro: Zahar.

Derrida, J., \& Roudinesco, E. (2001). Familles desordonnées. In De quoi demain... dialogue. Paris: Fayard et Galilée.

Fonseca, C. (2001). A vingança de Capitu: DNA, escolha e destino na família brasileira contemporânea. In Seminário "Estudos de Gênero face aos dilemas da Sociedade Brasileira”. São Paulo: Fundação Carlos Chagas, III Programa Relações de Gênero na Sociedade Brasileira.

Geertz, C. (1978 [1973]). O impacto do conceito de cultura sobre o conceito de homem. In C. Geertz, A interpretação das culturas (pp. 45-66). Rio de Janeiro: Zahar. 


\section{A Família como Ordem Simbólica}

Geertz, C. (1980). Transição para a humanidade. In F. Engels, C. Geertz, Z. Bauman, A. Leontiev, \& E Marcarian, O papel da cultura nas ciências sociais (pp. 21-36). Porto Alegre: Villa Martha.

Giberti, E. (1996). Lo família y los modelos empíricos. In C. Wainerman (Org.), Vivir en família (pp. 115-41). Buenos Aires: Losada/UNICEF.

Giddens, A. (1993). A transformação da intimidade: sexualidade, amor e erotismo nas sociedades modernas. São Paulo: Editora da UNESP.

James, A., Jenks, C., \& Prout, A. (1998). Theorizing childhood. New York: Teachers College Press, Columbia University.

Heller, A. (1996). Donde estamos en casa? In A. Heller, Una revisión de la teoria de las necesidades (pp. 123-59). Barcelona: Paidós.

Leal, O. F. (Org.). (1995). Corpo e significado: ensaios de Antropologia Social. Porto Alegre: Editora da UFRGS.

Lévi-Strauss, C. (1981 [1947]). Les structures elementaires de la parenté. Paris: Mouton.

Lévi-Strauss, C. (1974). Introdução: a obra de Marcel Mauss. In M. Mauss, Sociologia e antropologia (Vol. II, pp. 1-36). São Paulo: E.P.U; EDUSP.

Mauss, M. (1974 [1923-1924]). Ensaio sobre a dádiva: forma e razão da troca nas sociedades arcaicas. In M. Mauss, Sociologia e antropologia (Vol. II, pp. 37-184). São Paulo: E.P.U; EDUSP.

Marsiglia, R. M. G. (2003). Famílias: questões para o Programa de Saúde da Família (PSF). In A. Rojas \& M. A. Vitale (Org.) （pp. 169-174). São Paulo: IEE/PUCSP.

Rocha, E. (1994). O que é etnocentrismo. São Paulo: Brasiliense.

Rabinovich, E. (1995). O viés etnocêntrico: uma tentativa de analisar algumas questões de desenvolvimento infantil a partir do estudo de crianças no interior do Piauí. Revista Brasileira de Crescimento e Desenvolvimento Humano, 5(1/2), 60-65.

Rodrigues, J. C. (1979). Tabu do corpo. Rio de Janeiro: Achiamé.

Roudinesco, E. (2000). Por que a psicanálise? Rio de Janeiro: Jorge Zahar.

Roudinesco, E. (2003). A família em desordem. Rio de Janeiro: Jorge Zahar.

Sarti, C. A. (1995). O valor da família para os pobres. In I. Ribeiro \& A. C. T. Ribeiro (Org.), Família em processos contemporâneos: inovações culturais na sociedade brasileira (pp. 131-150). São Paulo: Loyola.

Sarti, C. A. (1999). Família e jovens: no horizonte das ações. Revista Brasileira de Educação, 11, 99-109. 
Sarti, C. A. (2001). A dor, o indivíduo e a cultura. Saúde e Sociedade. 10(1), 3-13.

Sarti, C. A. (2003a [1996]). A família como espelho: um estudo sobre a moral dos pobres (2a ed. rev.) São Paulo: Cortez.

Sarti, C. A. (2003b). Famílias enredadas. In A. R. Acosta \& M. A. Vitale (Org.), Família: laços, redes e políticas públicas (pp. 21-36). São Paulo: IEE-PUCSP.

Sarti, C. A. (2004). O jovem na família: o outro necessário. In R. Novaes \& P. Vannuchi (Org.), Juventude e sociedade: trabalho, educação, cultura $e$ participação. São Paulo: Editora Fundação Perseu Abramo.

Scavone, L. (1998). Tecnologias reprodutivas: novas escolhas, antigos conflitos. Cadernos Pagu, 10, 83-112.

Scavone, L. (Org.). (1999). Género y salud reproductiva en América Latina. Cartago: Libro Universitario Regional.

Recebido em 21.05.2003

Aceito em 1.03.2004 